\title{
On How to Arouse the Students' Learning Interest in Foreign Language Teaching
}

\author{
Yu Zhao \\ Department of Foreign Language, XingTai University, Xingtai, 054001, China
}

Keywords: foreign language teaching, learning interest, plot, life case, teaching method

\begin{abstract}
The students generally lack learning interest in the foreign language teaching, so it is very important to arouse their interest. This paper gives a simple introduction to the basic connotation of interest, discusses the correct understanding to interest mechanism in foreign language teaching, and focuses on how to arouse the students' learning interest in foreign language teaching from the aspects of applying new teaching methods, seeking for help from English songs and modern education technology, creating foreign language learning context, and introducing life cases, and etc.
\end{abstract}

\section{Introduction}

As we have often said, interest is the best teacher. In recent years, various teaching methods have been put forward and applied in the foreign language education field, and these methods all, focusing on mobilizing the students' initiative, arouse the students' learning interest to achieve the purpose of improving the foreign language teaching effect and level. When the students learn a foreign language, they often reject to learn and also have a certain barrier of understanding, etc., as a result, it is very hard for many students to improve their foreign language learning level. To make the students learn more autonomously and effectively, it is necessary to make them be interested in learning. It is an important topic currently on how to arouse the students' foreign language learning interest. This paper will make a discussion around this topic.

\section{Theory Overview}

\section{(I) Concept of interest}

Interest is a kind of emotion arousal status, and it is a tendency that the people know things or love some activities. If a person focuses on a thing for a long time under a certain orientation, it means that this person becomes interested in such thing. When a preponderant focus of excitation is formed in one area of cerebral cortex, and for the mutual induction of excitement and inhibition, other areas of the cerebral cortex will be restrained. It is manifested as learning interest in learning. The students are only passionate to the interested they are interested in, and they will be are more willing to learn and not give up easily for frustration.

With an interest, the people will be active to seek for the satisfactory knowledge and to understand the required approaches and methods. As long as the students become interested in learning, they will show enthusiasm to the activities to participate in, and be active to learn and explore, improve the efficiency, and develop new abilities. The famous educator Sukhomlinskii once said: “only when the knowledge becomes a factor of spiritual life to attract the people' s thinking and arouse the people' $s$ interest, it is true knowledge” . With interest, the people can cultivate all creative qualifies. Therefore, as long as the students' learning interest is aroused, their intelligence can be developed, their learning ability can be improved, and further their creativity can be stimulated.

(II) Classification of students’ interest in foreign language learning

In foreign language teaching, we are used to divide the students' interest into three types, namely, direct interest, indirect interest and stable interest, with different features, in which, indirect interest is relatively stable and stable interest is the sublimation of indirect interest. They are specifically shown as below: 
First, direct interest is most likely to stimulate the students' attention, to enhance the foreign language teaching effect, but it is hard to be kept for a long time, and only can play a certain role of guide and motivation in the students' foreign language learning. Therefore, direct interest will gradually bate and disappear with the weakening of students' curiosity and the deepening of teaching content;

Second, indirect interest has an advantage that it is generated among the students. Compared with the direct interest, it has a strong stability and is more helpful to the student' $s$ learning in an active way. In the foreign language teaching, it is required to emphasize the cultivation of indirect interest;

Third, stable interest. The generation of stable interest is sourced from indirect interest, and it could be said that understanding is the high level of interest. Stable interest can become an internal motivation for students' autonomic learning, and make the learning interest become an integral part of the students' personality development so that they will be longing for exploring the knowledge and enhance their cognition.

Thus, in foreign language teaching, the teachers shall pay attention to the cultivation of students' indirect interest and arouse the students to have keen interest in foreign language learning. When an indirect interest is formed, it shall be consolidated timely, and the teachers shall make efforts to transfer the students' indirect interest into a stable interest. In terms of foreign language learning, after a stable interest is formed, the students will take foreign language learning as a happy thing to do, and they will be pleased to explore and bold to make a breakthrough, so as to achieve the best learning effect. It is also the highest state pursued in cultivation of interest in the foreign language teaching.

\section{Ways to Arouse the Students' Learning Interest in Foreign Language Teaching}

In foreign language teaching, there are broad ways to arouse the students' interest. It is able to effectively arouse the students' learning interest and passion by creating situation, taking new teaching methods, using original English readings and English songs, and selecting the typical cases in the life, etc. Specifically, the following ways can be followed to arouse the students' interest in foreign language learning.

(I)Create a lively language context to arouse the students' learning interest

The objective of foreign language teaching is to cultivate the students to have cross-language communicative competence and foreign language application ability, etc. In foreign language teaching, with this as the talent cultivate objective, it is required to focus on cultivating the students' abilities in listening, speaking, reading, writing and translation based on application and practice. So the foreign language teachers are required not to follow the teaching materials blindly, but they shall create different teaching contexts based on teaching content and make the students participate in, so as to arouse their enthusiasm and learning interest maximally.

For example, in the foreign language teaching, the teachers may, based on the textbook content and in combination with the topics that the students are interested, create a certain learning context, and arrange the students to conduct role-playing in a group. For example, a classical dialogue can be selected, and the students will act as the protagonists of dialogue, to carry out training and perform a short play. All the contents in the short play shall be talked about in foreign language. In this way, the students can show a great enthusiasm and initiative. In the lifelike teaching context, the students not only learn the foreign language but also experience the work as a receptionist and learn the knowledge except language. In addition, when the teachers create a context, they shall select a distinct theme and character setting, and highlight the interestingness of the context created. To create a context, it is required to highlight the students' dominant role and focus on how to arouse the students' interest. If the context established is far from the objective of foreign language teaching, it will have more harm than good. 
(II) Use new teaching methods to arouse the students' learning interest

In the foreign language teaching, the teachers shall develop their creativity and flexibly organize the teaching activity, but not adopt a single teaching method, to make the classroom teaching mode substantial and rich in changes, so that the students' interest and initiative in foreign language learning can be stimulated better, therefore increasing the students' learning initiative and making them more confident. To stimulate the students' learning initiative and arouse their interest in foreign language learning, the students shall do from the following aspects:

1. Pay attention to classroom teaching design and add the interestingness of classroom teaching

Interestingness is an indispensable trait in foreign language teaching. The teachers with flexible teaching forms are easier to grasp the students' minds in the classroom, alleviate the students' mental pressure through livingly and interesting lecturing methods and attract their attention to the teachers' classroom teaching, so that the students will feel relaxed and comfortable and their learning will become more effective. For example, according to different teaching contents, the teachers can organize different games such as situational dialogue and role-playing in the classroom to develop the students' creativity, reflect their personality characteristics, and make the students learn knowledge and grasp the language in the playing, really reflecting edutainment. In addition, the teachers may add some interesting words, idioms and proverbs in the teaching. Anyway, a teacher who is good at arousing the students' interest is able to make the classroom lively and interesting with his/her enthusiasm and wisdom and make them fix concentration on the classroom.

Certainly, no matter what teaching methods are adopted to assist the teaching, the teachers shall give a full play to the students' subjective initiative, and they shall take the methods of Student-centered Teaching. The students are not only the partners of teachers in the teaching, and also the direct designers of some classroom activities. The cultivation and improvement of students' interest in foreign language learning cannot be achieved in a short time, and it needs the accumulation of time. Therefore, the foreign language teachers shall be aggressive, good at using the teaching reform experience for reference, make a summary continuously, widen their scope of knowledge through various ways, promote their professional proficiency and teaching ability, and improve their personal quality and personality, so as to bear the responsibility of foreign language teaching better.

2. Simplify the teaching methods to reduce the students' learning disabilities

According to Sukhomlinskii, it is is an important task for teachers to cultivate the students' learning interest and appetite for knowledge. The students' interest in a certain thing is not inborn, but generated under the joint influence of postnatal environment and acquired education. It can be discovered through analysis that those students who have a poor academic performance for lacking interested in foreign language and learning motivation all follow a circle of way which is " feeling difficulty $\rightarrow$ lacking interest $\rightarrow$ getting a poor academic performance $\rightarrow$ become much less interested in learning $\rightarrow$ getting a poorer academic performance." The teachers' teaching shall be based on the current situation that the students have a weak foundation in foreign language learning, but not take such teaching equal to that in colleges and universities.

In the teaching, in addition to cultivating the students' sense of foreign language through making students have training of reading, listening and imitation, the writer has fully considered the difficulties that the student may meet in the learning when preparing lessons, to make the teaching more targeted. For example, For example, it is common that the students feel hardest to grasp the tenses of verb in foreign language learning, the writer takes the method of sentence-making and uses some simple sentences to make the students understand and speak, and moreover, uses different tenses under different situations, to show the meaning of tenses in an understandable way, so that the students will understand more easily, and finally combine the precious learned tenses with the currently learned ones to understand their differences and links. Therefore, the above content can be summarized in the following words: first listen and speak, then read and write; exercise more and summarize timely; and comprehend by analogy. In this way, the teaching effect 
will be obviously improved.

(III) Based on the students' life reality, understand their concerns

Based on the students' age characteristics, games are not necessarily what they need, but they really need to talk about the topics they are interested in and get the knowledge to increase their knowledge. Therefore, apart from being familiar with the teaching content, the teachers shall get along with the students as their friends, grasp the students' interest points, know the various activities and fashion elements concerned by the students, and add the materials which are welcomed and popular in the life into the classroom teaching. In the classroom, the teachers also may, based on the teaching content, introduce the students culture and customs of some foreign countries, teach them to learn English songs, arrange them to watch original English films, organize free talk and other activities, and etc., to stimulate their interest and enthusiasm, so that the students will devote to the practice of language learning with a good learning state.

For example, it is recommended to introduce some popular English songs by use of the patches of time. Through the opportunity of Titanic releasing, I introduced the song of this film "My Heart Will Go On” , and as a result, almost all students recorded the lyrics and many even recited them. This song is melodious, with moving lyrics. In this way, the students enjoyed the music and improved their music appreciation level, and meanwhile their listening was improved. In addition, their interest in foreign language learning was aroused. If the teachers want to do a good job in interest migration, they shall pay attention to the following aspects: first, understand the students' interest points and utilize their interest points, to seek the origin of interest migration; second, discover the links between the students' original learning interest and the learning activities, to seek the method of their interest migration; and third, make the students feel the pleasure of learning when they contact the learning activities they are interested in, to make their interest migration easier.

(IV) Show a demonstration of reading with emotion, to stimulate the students' visual sense

In the foreign language teaching classroom, the teachers may at a right time choose a certain part in the textbook or classics to reach emotionally. Such reading is different from the traditional one, but it is a kind of reading which is cadenced and rich in feeling based on the reader' s fully understanding to the connotation of the text, to attract the students' hearing and enhance the interestingness of teaching. When reading with emotion, the teachers shall pronounce vowel and consonant correctly and pay attention to the use of liaison, sound omission and swallowing. In the course of reading, they shall pay attention to the accent of words and phrases and also cannot ignore the logical accent in the text; adjust the voice and emotion based on text content and emotion in proper time; and change the status based on the changes of feelings in the text, so that the students will be easier to accept and get knowledge.

In addition, the students can be arranged to participate in reading. By experiencing the course of reading, the students will develop interest in foreign language learning. Moreover, the teachers may tell classic stories in humorous language to arouse the students' interest, and express in plain language and with rich body language, so that the students can not only experience an enjoyment in visual sense, but also in auditory sense, and etc. Therefore, the students can grasp some words, phrases and classical sentences in the atmosphere of happiness.

\section{Conclusion}

In foreign language learning, it is very important that the students can become interested in language learning, improve their learning level and quality. In the changing new era, to arouse the students' learning interest, it is required to catch the students' eyes, promote the students' spiritual development, and stimulate the students' desire for learning. There is a variety of ways to arouse the students' interest in foreign language learning. With the wide application of multimedia, English magazines, original English songs, and lively life cases, the students' learning interest is greatly aroused. As a saying goes, “All roads lead to Rome.” The ways to arouse the students' 
interest are not only limited to those mentioned herein, and the wide educators should continuously explore and innovate in the teaching practice.

\section{References}

[1]Xing Yaqin. Three Dimensions of Metaphorical Competence —Building of Foreign Language Learning Network with Metaphorical Competence, Language Competence and Communicative Competence [J]. Border Economy and Culture, 2014, 03:102-104.

[2] Pan Lijuan. On Reconstruction of Thinking in Foreign Language Learning [J]. Journal of Changchun Normal University, 2014, 03:156-157.

[3] Guo Xin. Influence of Mother Tongue Transfer on Foreign Language Learners' Spoken Language and Strategy Research [J]. Modern Communication, 2014,01:181.

[4] Hu Xi. Touch-Interface Interactive Design of Foreign Language Learning Based on Customer Experience [J]. Design, 2013, 11:109-110.

[5] Li Xue. Research on Strategy of Arousing, Cultivating and Keeping the Students' Interest in Foreign Language Learning [J]. College English (academic edition), 2007, 01:412-414. 